\title{
COVID-19 \& Prospects of Online Work from Home Using Technology: Case from India
}

\author{
https://doi.org/10.3991/ijoe.v17i09.23929 \\ Bibhu Prasad Sahoo, Ankita Gulati $\left.{ }^{\bowtie}\right)$, Irfan U1 Haq \\ University of Delhi, Delhi, India \\ aankita.gerediffmail.com
}

\begin{abstract}
The outburst of the pandemic COVID-19 in 2019 from the land of China to the entire world has brought a major change in people's living style. The severity of the disease is so much that more than 20 million people are affected by it worldwide. The recommended preventive measure to avoid the spread of this fatal disease is to maintain social distance leading to a significant economic disruption that could submerge the economies globally. However in order to keep the economies moving, the work from culture is adopted globally wherein the employees are connected via the internet and the work continues to happen. This paper aims to discover how people adopt such an attempt in the working culture. Also, the purpose of the paper is to find out its bearing on the employees' working capacity and whether they would like to continue with this arrangement in the future. The research employs primary data collected from 400 employees across various industries who are currently working from home. The research proposes advantages and challenges in working from home with a majority of employees preferring the method.
\end{abstract}

Keywords-COVID-19, Information and Technology (IT), machine learning, virtual connect, Work from home (WFH)

\section{Introduction}

The first case of Covid-19 in India was reported in January 2020 in Kerala, and since then, the number of cases is increasing rapidly. In India around 11 million people has suffered from the disease (till February 2021). India being the second populous country with 1.34 billion people, it becomes all the more difficult to control the spread of this deadly virus named SAR-COV-2.

To impose social distancing Janta Curfew (a 14-hour lockdown) was ordered on March 22nd, 2020. In order to reduce the transmission of the virus, Indian government had implemented a 55-day lockdown throughout the country, which started on March 25th, 2020. The industrial sector in India got obstructed due to the outbreak of this pandemic, which made the economy show a downward trend as it is one of the major contributor in India's GDP. The people started living in distress and are currently very cautious about engaging in business activities and traveling. 
Economists globally believe that the influence of Covid-19 will be negative on the economy. The hospitality and tourism industry in India has witnessed a steep downtrend post the announcement of lockdown by the government of India. This is in sync with the global trend with the railways, road and airways transport industry also facing a slowdown.

With the lockdown of malls, cinema halls, spas, and other luxurious services, the consumption expenditure has decreased, leading to a high saving rate. Higher savings also leads to slow economic growth. This is because the multiplier effect of consumption gets reduced. Furthermore, industrial production has fallen due to lockdown imposed on various industrial units. Even after unlock, the production level is low as the working hours have been reduced because of disruptions in demand for goods globally. Also, labourers have moved to their hometowns, making the production suffer.

With the poor supply chain, lack of consumption expenditure, etc. the burden of the Indian economy to be able to stand depends upon agriculture and service sector. The service sector, to be on rolls and keep up the pace, has started a culture of working from home. Herein the employees connect using various applications or via the server in a digital manner or virtually. This has helped the companies to achieve their targets in time.

The concept of work is, though not new, in the MNC culture. Amidst the pandemic, almost every institution, including private/semi-private/government, has started WFH to keep the work going. For these online classes, online webinars, online training, online conferences method is adopted by almost every institution.

However, this remote working accommodation brings in inequality among workers as it is only suitable for a few industry types and to a few classes of employees. As per the survey from Canadian General Social Survey (GSS) 2015, the higher the person's salary the more likely it is that they can do work from home. Also, sectors like manufacturing, art, creation, culture, natural \& applied science, agriculture, and related production do not support work from home. It's the sales \&service, business, finance \& administration which can comfortably accommodate this change.

Google has already made a move by allowing most of its employees to work from home till June 30th, 2021, for the roles that don't need to be in office. Amazon too has extended its WFH policy till January 2021. The companies are empowering regional teams to take decisions. They are putting in place better IT systems, data security processes, and training employees for this. They are focussing on increasing the broadband bandwidth and providing the necessary infrastructure for the same. It is hopeful that with India's unlock 3.0, the business activity will see a push. Those companies that can afford this accommodation are playing safe and ensuring that business is as usual with all necessary infrastructure and systems.

\section{Review of Literature}

The concept of work from home is present at top-level management since the 1980s [1]. The emergence of the oil crisis was one major push to the acceptance of organizational innovation, namely work from home [2]. In the 1980s, these arrange- 
ments started to get popularity with the emergence of new technology, personal computers, and network systems development.

Single parents or people who have major personal responsibilities could solve their issues while working from home and creating a work-life balance [3]. The environment Board of America has tried and offered enticements to companies to allow its employees to work from home. It could lead to lesser traffic and henceforth low population emissions [4].

With a reduction in barriers to communication among workers due to the rapidly increasing technology, the work from home has become easier for employees global1y. The study also mentioned that over a $20 \%$ increase in telecommuters has happened in a span of a year, showing a preference for this arrangement [5].

The impact of work from home on the working outcomes on the attitude of employees is positive. The research explains that the work stress among employees is less, which leads to an increase in their productivity due to work from home [6]. However, the lack of communication among colleagues leads to a negative impact on employees' overall job satisfaction. The top-level management also feels a little resistant to this arrangement as it leads to a lack of assessment of the employees and believes that their productivity falls due to this arrangement [7].

The invisibility of workers in the office space and working from home makes it difficult for the supervisors to keep a check on their work and to lead to less productivity and slower progress in career [8]. A study was conducted on the online faculty to examine their work satisfaction by taking online classes. The faculty find more happiness if they can separate their work from home. Also, they cannot fulfill their social needs for which virtual communities were formed [9].

Due to the improvement of information and communication technologies, the recurrence rate of work from home accommodation in firms has been augmented over the past few years $[10,11]$. In 2009 , as per a study, there is almost a $20 \%$ increase in work from home among employees in various German firms for at least a couple of days in a month. As a result, the employees get ample sovereignty to schedule and organize their work strategy [12]. The higher is the flexibility to work that the employees understand, the more they get motivated to improve their work effort $[13,14]$.

The companies which offer flexibility \& autonomy in their working environment tend to get the best minds and can retain their efficient employees longer [15]. Employees respond to facilities like the availability of working from home with a reciprocal behaviour of putting "additional" efforts in their work [16]. Also, it is examined that due to fewer distractions by colleagues at home and an unobtrusive environment, employees feel less stressed while working from home [17, 18].

Various studies have been done to determine the influence of work from home on the productivity of employees. All of the reviews figured out that there is a positive relationship between employee productivity and working from home [15, 17, 19]. Also, studies using field experiments to elucidate cause and effect relationship between work from home and employees performance showed the same results and encouraged companies to provide this facility of working from home [18, 20]. 


\section{Objectives and Hypothesis of the research}

\subsection{Objectives of the research}

With the view of research done in the past, it becomes essential to discover how this pandemic has forced the concept of working from home and finding out how the employees are bending to this arrangement.

This research aims to determine the factors that can induce work from home in the future. The research is validated by undertaking various statistical tests and analysing the primary data collected by 400 employees currently working from home. Besides general purpose of research the following specific objectives are also mentioned:

- To verify whether gender has any impact on the preference of work from in future.

- To evaluate about which industry type is more flexible in adapting this new normal situation of working from home in future.

- To elucidate the whether those who are doing work from for the first time believes that such accommodation will be validated by their company later also.

- To understand whether cost savings are occurring and hence employees prefer to work from home even after this pandemic is over.

- To find out whether employees are facing problem while working from home.

- To clarify that the employees still find it easy to connect with each other through remote working.

- To explicate if there is an improvement in work life balance while working from home making it a win-win situation in future

\subsection{Hypotheses}

H1: there is a significant relation between future preference of work from home and (a) gender of the employee; (b) industry type; (c) the cost savings due to work from home; (d) employee productivity; (e) work life balance; (f) peer connectivity.

\section{$4 \quad$ Limitations of the research}

The research is based on the responses of the employees only. Hence, it does not take into account the company's point of view towards work from home. The research also suffers the limitation of very less number of respondents and that too from few industry types only. The spectrum of respondents taken was all well equipped with latest technology and appliances. The study also suffers the basic shortcomings of survey research such as biased answers, lack of personalization, misinterpretation of questions etc. 


\section{$5 \quad$ Research Methodology}

The research methodology used in the study is quantitative. In order to examine cause and effect interactions among variables and test relationships a methodical study is followed. To collect data a descriptive survey design was used. The information is collected by questionnaires that were self-administered and distributed to employees belonging to different industry type through various online mediums.

The selected technique is descriptive surveys because it helps in providing accurate characteristics of the variables say the opinions, behaviour, beliefs of the respondents. The study was steered online \& 400employees' data was collected.

The data analysis of this research is presented in quantitative manner. Data was analysed using regression models, crosstabs and various other descriptive statistics with the help of excel spread sheets and R software.

The rationale for choosing such research methodology is to find out that employee's preference for work from home in future depends upon which of these factors and which among these factors has the major impact on it.

Since the preference is a binary classifier (yes or no), a logistic model is used and the regression equation used is given in equation 1:

$$
P=\frac{1}{1+e^{-Z}}=\frac{1}{1+e^{-\left(X_{0}+\beta_{1} X_{1}+\beta_{2} X_{2}+\cdots \cdots \cdots \cdots+\beta_{n} X_{n}\right)}}
$$

Where,

$\mathrm{P}$ is the probability that dependent is yes $=1$,

Dependent variable is future preference for work

$\mathrm{X}_{1}, \mathrm{X}_{2}, \mathrm{X}_{3}, \ldots \ldots \ldots \ldots \ldots \mathrm{X}_{\mathrm{n}}$ are the independent variables

Entire data analysis was performed in $\mathrm{R}$ software. The research was based on advanced machine learning algorithms to derive meaningful insights and statistical significance of the important drivers impacting the work from home preference of each individual.

The survey questionnaire was designed on 16 questions in which future scenario preference was kept the dependent variable while the rest 15 parameters were kept as independent features. The first step of the approach is to rank each of the independent covariates in decreasing order of their importance or relevance to define the dependent variable. This provides the top 10 most essential drivers kept for regression analysis. For this purpose random forest algorithm is used, one of the most widely applied machine learning techniques in binary classification. It is based on the concept of decision trees i.e. when a large number of decision modelling trees, which are relatively uncorrelated, come together to form a singular model they will outperform any individual constituent model. This is because each model cancels out the bias and error of the other model as they are independent. Then the mean decrease in accuracy parameter is check. This calculates the decrease in prediction power of the variable 
when it is randomly permuted in the model against its original ordering with the dependent variable. The variables become more critical when the values become high.

Since the response variable was a binary outcome of whether work from home will be preferred in the future or not, logistic regression to predict the outcome depending upon various demographic, attitudinal, preference, and impact variables is used given above. Given that a model may be biased with high variance, the logistic regression model is enhanced using bootstrap aggregation or simply what is called bagging. It is a type of ensemble modelling, a category of advanced machine learning algorithms which is made of two concepts - bootstrap which means estimating a quantity from a sample of data with or without replacement and aggregation which essentially repeats the process multiple times and individual model predictions are aggregated to make a final accurate prediction. Bootstrap aggregation is used to combine various ensemble models via mean or mode, depending on the problem. In this case an average of predictions across each model is taken. This method helps to reduce the variance in the model's forecast from the small sample. It mitigates the issue of small sample size by repeating the draw of sample $\mathrm{n}$ number of times from a given population so that over time the average replicates the actual population. Bagging can be done in two ways. Firstly, subsampling in the number of observations and secondly in terms of covariates in the independent variables.

\section{$6 \quad$ Analysis and Interpretation}

A survey was conducted to study the impact of COVID on work from home culture. Four hundred respondents took part in the survey, which was distributed through online digital mediums like email and social networking sites. The survey data was kept entirely anonymous, with no personal data being captured for the individual participants. The data is being studied at the aggregated level to dissect to derive insights, draw actionable strategy for the near future, and impact the society and the industry in general. A total of 15 questions were asked, including information like gender, industry type, preferences, and impacts of doing work from home.

Figure 1 presents some high-level survey exploratory data analysis that reveals the responses and preferences. As can be seen from the data, earlier 39\% of the people had the option of work from home, which was almost doubled to $87 \%$ during the lockdown. Within that $68 \%$, a good majority of people prefer to continue to do so in the future, which shows that this could be a trend and a reality in the coming time. The respondents are covered from a mix of industries, and about two-thirds have experienced a reduction in expenses and believe that their performance is not impacted. In terms of maintaining the connection between their colleagues, there is no definite pattern, as can be seen from a mixed response and work-life balance where the answer is divided between better and worse. In terms of demographics, one-third of the population was female, who also throws a stark glare at the share of females in the working people of the country.

Apart from the visual graphs represented in figure 1, it can be seen that Microsoft Teams is the predominant medium of office communication, with $75 \%$ of the people 
using it during work from home. Respondents were asked whether working from home anyhow impacted the timelines for their projects, and interestingly, $60 \%$ said no. Given that work from home is not a prevalent concept in the society; the questionnaire asked whether people felt that working from home was perceived as free for household chores by their family members or society at large. Surprisingly $50 \%$ of the sample said yes. It is maybe this feeling that is stopping the people from working from home, which should not be the case given that it is seen about two-thirds majority are comfortable working from home without any impact on performance.

The figure representing the exploratory data of the respondents is given in fig. 1:

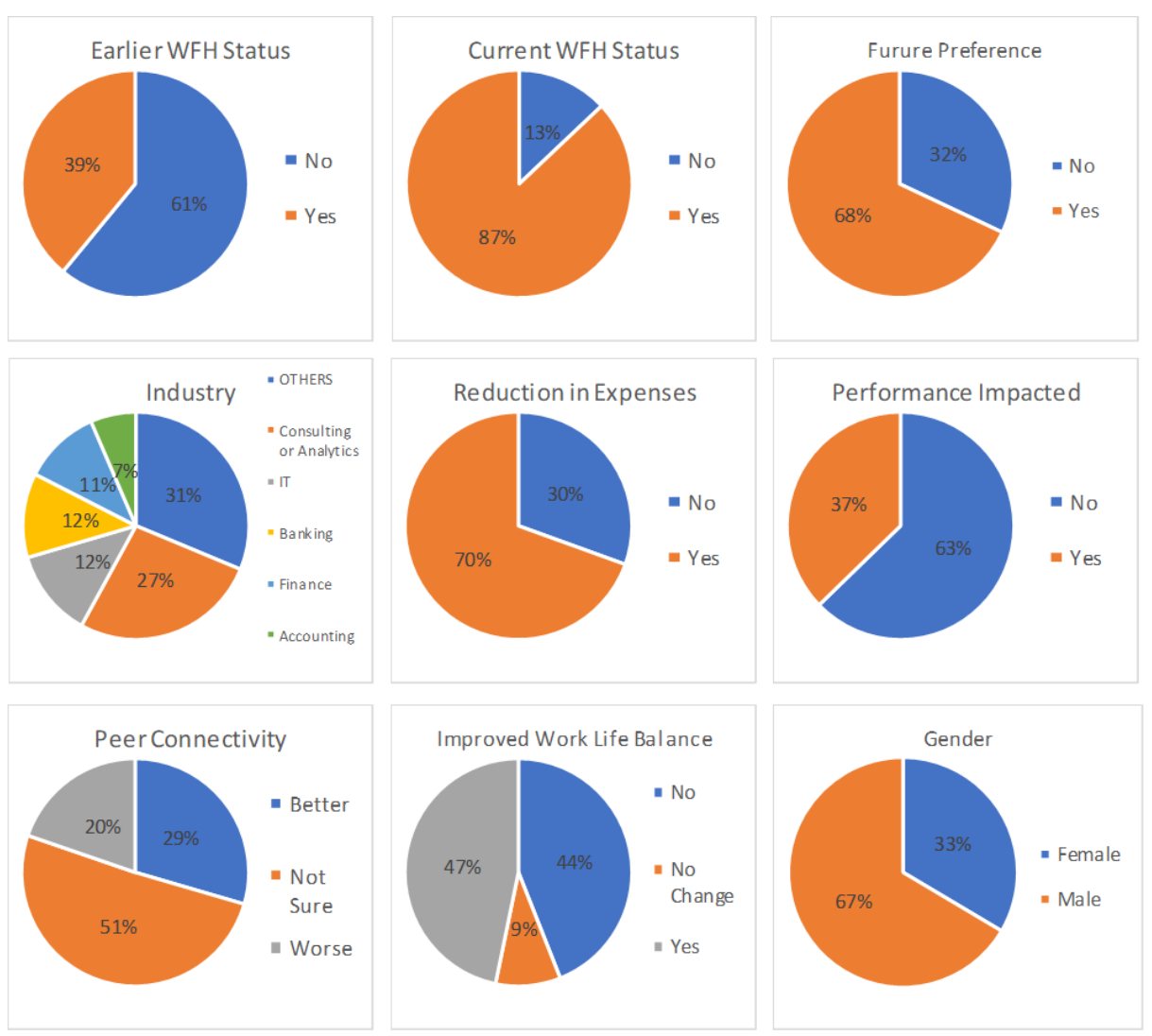

Fig. 1. Exploratory data analysis from the survey data of 400 respondents

The random forest classifier in $\mathrm{R}$ on all 15 variables together was built; to create 100 trees each taking a sample of $50 \%$ random values from the pool of 400 observations. The table 1 depicts the output from the random forest variable importance function, where the top 10 drivers are finally selected for the logistic model analysis.

The table 1 suggests that the most important factor that induces work from home is whether the employees find it tough to do work from home and the work life balance which employees are always keen to get. The other important factors are the availabil- 
ity of this facility earlier by the companies, effect on the performance, peer connectivity, and gender. Also, the research proposes that due to cost savings the employees and companies are more interested in this method making it a trend in almost every industry in the near future like finance, IT, banking, education, health etc.

Table 1. Top 10 drivers

\begin{tabular}{|clr|}
\hline S.NO & VARIABLE & IMPORTANCE \\
1 FIND_WFH_TOUGH & 25.17 \\
2 IMPROVED_WORK_LIFE_BALANCE & 22.43 \\
3 PREFERENCE & 21.95 \\
4 INDUSTRY & 20.65 \\
5 COMPANY_COST_SAVING & 18.83 \\
6 WFH_EARLIER & 16.41 \\
7 PERFORMANCE_AFFECTED & 15.21 \\
8 PEER_CONNECTIVITY & 14.22 \\
9 TIMELINES_RELAXED & 13.36 \\
10 GENDER & 12.99 \\
11 APPS & 12.72 \\
12 PERSONAL_CONTACT & 11.48 \\
13 PERCEPTION_OF_BEING_FREE & 11.45 \\
14 UR_EXPENSES_REDUCE & 10.27 \\
15 CURRENT_WFH & 8.61 \\
\hline
\end{tabular}

Further, while building the bagged logistic regression for all the iterations of the model, a random sample of about $50 \%$ observations without replacement to ensure equal weights to each observation is taken. The process was reiterated 100 times which means 200 observations were picked out of 400 observations randomly and then repeated 100 times. This gave 100 different datasets of 200 observations each with a given set of dependent and independent variables. Then secondly, in terms of the covariates, since the model is a classification model, benchmark number of predictors (p) to be used is about square root of total number of variables (n):

$\mathrm{p}=(\mathrm{n})^{\wedge(1 / 2)}$ which corresponds to $(10)^{\wedge(1 / 2)}=3.16$, taking ceiling round off to 4 .

Now post dimension reduction through random forest, the database is left with top 10 predictors, so a sample of 4 random variables at a time is taken. This meant that 210 pairs of combinations of features are used to build the model which is ${ }_{10} \mathrm{C}_{4}$ are generated. 
Combining the steps one and two from the above approach, it meant building $210^{*}$ $100=21,000$ models of logistic regression on random samples of survey data collected from 400 respondents. Building thousands of models entails a lot of run time and computing power, hence a concept of parallelization in $\mathrm{R}$, which is exactly used for the purpose of automating, fastening and doing parallel processing is used. It involves distributing the tasks separately to the cores on the computer machine to work parallelly. In this case one pair of combination for which 100 iterations would be run is a task and the laptop used had 8 cores which meant that at a single time 8 models could be built. R uses the library "do Parallel" to run this using lapply function supplemented with parallel cluster cores.

The results of the logistic model are depicted in table 2:

Table 2. Regression results

\begin{tabular}{|l|r|r|}
\hline VARIABLE & TIOG_OD \\
\hline CO_COST_SAVING_No & $-34 \%$ & $(0.53)$ \\
\hline CO_COST_SAVING_Yes & $133 \%$ & 0.78 \\
\hline FIND_WFH_TOUGH_Sometimes & $-79 \%$ & $(1.97)$ \\
\hline FIND_WFH_TOUGH_Yes & $-94 \%$ & $(3.36)$ \\
\hline GENDER_Male & $36 \%$ & 0.26 \\
\hline IMPROVED_WORK_LIFE_BALANCE_No Change & $74 \%$ & 0.39 \\
\hline IMPROVED_WORK_LIFE_BALANCE_Yes & $475 \%$ & 1.65 \\
\hline INDUSTRY_Banking & $-60 \%$ & $(5.47)$ \\
\hline INDUSTRY_Consulting or Analytics & $-32 \%$ & $(4.88)$ \\
\hline INDUSTRY_Finance & $-91 \%$ & $(6.82)$ \\
\hline INDUSTRY_IT & $-76 \%$ & $(6.03)$ \\
\hline INDUSTRY_OTHERS & $-79 \%$ & $(6.01)$ \\
\hline PEER_CONNECTIVITY_Not Sure & $-3 \%$ & $(0.11)$ \\
\hline PEER_CONNECTIVITY_Worse & $-29 \%$ & $(0.49)$ \\
\hline PERFORMANCE_AFFECTED_Yes & $-35 \%$ & $(0.52)$ \\
\hline PREFERENCE_Work from home & $1298199147 \%$ & 6.29 \\
\hline PREFERENCE_Work from office & $-86 \%$ & $(2.25)$ \\
\hline TIMELINES_RELAXED_Sometimes & $-19 \%$ & $(0.29)$ \\
\hline TIMELINES_RELAXED_Yes & $50264770 \%$ & 1.09 \\
\hline WFH_EARLIER_Yes & $238 \%$ & 1.17 \\
\hline
\end{tabular}

The table above has three columns - 1) VARIABLE, which is the independent driver with the coefficient for each possible class of value, 2) ODDS, which represent the $\%$ change in odds of the dependent variable for 1 unit increase in independent or change in class from the base position, 3) LOG_ODDS, which is the direct coefficient from the log model providing the change in log odds.

It can be seen that the employees believes that the companies are saving costs due to work from home, then the odds (probability of success by failure) increases by $133 \%$ versus if they are not sure of it and similarly it decreases by $34 \%$ if the compa- 
ny is not saving costs as the company definitely will not promote WFH scenario in that case. Another variable is if people find tough to do work from home and if the response is "yes", then the odds of continuing work from home reduces by $94 \%$. Being a male increases the odds of working from home in future by $36 \%$ versus a female. A big factor of continued work from home is improved work life balance, where it can be seen that the odds increase a staggering $475 \%$ if it improves because people then can save on the wasteful travel time, fatigue and expenses and devote to personal hobbies or family time leading to higher productivity. Across industries it can be seen that a negative change in odds, highest being for finance industry, and lowest being for analytics industry where possibly the extent of automation and digitization is already the highest. An important and integrated element of office life is peer touch and connectivity, which leads to a $29 \%$ reduction in odds of working from home if people feel it is hampered. Impact on performance leads to a $35 \%$ decrease in odds where as if the employees already had a previous work from home facility, it lead to a $238 \%$ increase in odds as both the company and the employees are familiar with the system and work flow. The two very large values of change in odds basically reflect that the two possibilities are very rare with all other variables at their base options.

Finally the accuracy of the models that are built is also checked by taking average of all the 21,000 models to arrive at the final accuracy figure as well as creating the confusion matrix shown in table 3 :

Table 3. Confusion Matrix

\begin{tabular}{|l|c|c|c|}
\hline \multirow{2}{*}{ CONFUSION MATRIX } & \multicolumn{2}{|c|}{ PREDICTED } \\
\cline { 3 - 4 } & & $\boldsymbol{Y E S}$ & $\boldsymbol{N} \boldsymbol{O}$ \\
\hline \multirow{2}{*}{ ACTUAL } & $\boldsymbol{Y E S}$ & 122 & 14 \\
\cline { 2 - 4 } & NO & 31 & 33 \\
\hline
\end{tabular}

The model gives an accuracy of $77.25 \%$. As can be seen above the confusion matrix is built of four components:

TP (True positive,122) - both actual and predicted are true

TN (True Negative, 33) - both actual and predicted are negative

FP (False Positive, 31) - predicted is positive, but actual is negative

FN (False Negative, 14) - Predicted is negative, but actual is positive.

\section{$7 \quad$ Discussions and conclusions}

The impact of COVID-19 is significant as it has brought a shift in the working culture. The impact is so deep that it could lead to reform in work and working patterns in almost every sector. The institutions and employees have grabbed the best possible way to be in the system and keep the action going i.e., working from home. With 
more passing days, this method has been appreciated and accepted by everyone. Its impact is visible in the banking sector, as well. Apart from online banking, which was already a part of the system, the big push is now given to digitization in every aspect like loan approvals, account an opening or KYC, etc. Significant growth in the IT sector can be seen with more and more investments are happening in this sector. Software, network connections, and other applications are now an integral part of the working culture. Along with these changes, the industry trend has been changed and preference is given to digital advertisements and e-commerce.

Work from home not only keeps the economic growth in pace but has also brought social and economic benefits to society. With no traveling, the pollution level and traffic have been reduced. Also, companies do not need office space and furniture for their employees. The companies do not have to endure the cost of other facilities like air conditioners, internet, wi-fi, canteens, etc. This can be concluded that this method of work from home will now become more popular among the employers.

It can also be brought into the picture that this "new normal" is benefitted by a particular group of people with disabilities. People with disabilities are often at a disadvantageous position at workplaces. Research shows that people with disabilities faces various negative typecasts and attitudes and are often at a greater risk of getting laid off in a crisis. Clearly, by allowing people to work from home employers do not have any excuse not to welcome such group of people, especially with those of mobility impairments. This may help them in ensuring fair pay and can make them free from the irrelevant stereotypes faced by them.

Besides all these advantages there exist specific ill effects due to work from home. The employees feel isolated and disoriented from their peers. Also, the enthusiasm to work and satisfying their social needs is disappeared. Communication problems and difficulty in monitoring employees is also present. There are specific industries that are severely influenced by this change. The real estate market in India has hit hard due to this method of working from home. With nearly half a million square feet area being vacated by the companies, there is a significant fall in the rental cost leading to the slowdown of this industry. The construction jobs have also been shrunken, leading to massive unemployment.

In India, around $40 \%$ of start-ups are temporarily shut or on the brink of shutting down. This is because of the shrunken market and its demand. From cab aggregators and food tech to hospitality and travel, they have been facing an endless number of challenges to withstand their business in terms of liquidity, attracting investors, etc. There is a visible dip in the investments in the last few months, and the start-ups have been struggling with their remaining cash flow. Consequently, various start-up employees have been laid off, while others have been asked to go on temporary leave.

India being a dominant service economy wherein working from home will not lead to a sudden downfall in the growth. Hence, it is believed that to keep the work going, the companies should start investing in their Information and Technology (IT) rather than in physical assets. Also, the employees should prepare themselves for this change. The people at large are also advised to attain access to all these digitized facilities because sooner or later, this method will be the best available strategy to grow and reduce costs (both social and economic). The analysis that is presented 
above helps the companies and the employees to address these challenges. Also, the firms can find out the essential factors to align on the expectations and best practices to derive optimal productivity for both entities.

\section{References}

[1] Albrecht, Sandra. (1982). Industrial Home Work in the United States: Historical Dimensions and Contemporary Perspective. Economic and Industrial Democracy - ECON IND DEMOCRACY. 3. 413-430. https://doi.org/10.1177/0143831x8234003

[2] Nilles, J. \& Carlson, F. \& Gray, P. \& Hanneman, G. (1974). The TelecommunicationsTransporation Tradeoff. Final Report, 1 Jul. 1973 - 31 Dec. 1974 University of Southern California, Los Angeles. -1.

[3] Bailyn, Lotte 1993. Breaking the Mold: Women, Men and Time in the New Corporate World. New York: Free Press. Bureau of National Affairs. 1991.

[4] Clean Air Act 1992 governed by United States Environmental Protection Agency

[5] Calem, "Working at Home, for Better or Worse," The New York Times, Sunday, April 18, 1993, Business Section, pp.1, 6.

[6] Kraut, Robert. (1994). Predicting the use of technology: The case of telework.

[7] Olson; Margrethe H. 1989. Work at home for computer professionals: Current attitudes and future prospects. ACM Transactions on Information Systems (TOIS) 7(4): 317-338. https://doi.org/10.1145/76158.76891

[8] Perin, Constance. "The moral fabric of the office: Panoptical discourse and schedule flexibilities." Research in the Sociology of Organizations, 8, 1991, pp. 241-268.

[9] Stadtlander, Lee \& Lacivita, Lori \& Sickel, Amy \& Giles, Martha. (2017). Home as Workplace: A Qualitative Case Study of Online Faculty Using Photovoice. Journal of Educational Research and Practice. 7. 45-59. 10. https://doi.org/10.5590/jerap.2017.07. 1.04

[10] Shamir, Boas, and Ilan Salomon. 1985. Work-at-home and the quality of working life. Academy of Management Review 10(3): 455-464. https://doi.org/10.5465/amr.1985. $\underline{4278957}$

[11] Baruch, Yehuda. (2002). Teleworking Benefits and Pitfalls as Perceived By Professionals. New Technology, Work and Employment. 15. 34 - 49. https://doi.org/10.1111/1468-005x. $\underline{00063}$

[12] Holman, David \& Totterdell, \& Axtell, Carolyn \& Stride, Chris \& Port, \& Svensson, \& Zibarras, Lara. (2012). Job Design and the Employee Innovation Process: The Mediating Role of Learning Strategies. Journal of Business and Psychology. 27. 177-191. https://doi. org/10.1007/s10869-011-9242-5

[13] Hackman, J. Richard, and Oldham, R. Greg. 1976. Motivation through the design of work: Test of a theory. Organizational Behavior and Human Performance 16(2): 250-279. https:// doi.org/10.1016/0030-5073(76)90016-7

[14] Bailey, Diane \& Kurland, Nancy. (2002). A Review of Telework Research: Findings, New Directions, and Lessons for the Study of Modern Work. Journal of Organizational Behavior. 23. 383 - 400. https://doi.org/10.1002/job.144

[15] Dubrin, A.J. (1991). Comparison of the Job Satisfaction and Productivity of Telecommuters versus in-House Employees: A Research Note on Work in Progress. Psychological Reports, 68, 1223 - 1234. https://doi.org/10.2466/pr0.1991.68.3c.1223 
[16] Fehr, Ernst \& Gächter, Simon. (2000). Fairness and Retaliation: The Economics of Reciprocity. Journal of Economic Perspectives. 14. 159-181. https://doi.org/10.1257/jep. $\underline{14.3 .159}$

[17] Bélanger, France. 1999. Workers' propensity to telecommute: An empirical study. Information and Management 35(3): 139-153. https://doi.org/10.1016/s0378-7206(98) $\underline{00091-3}$

[18] Bloom, Nicholas, James Liang, John Roberts, and Zhichun J. Ying. 2015. Does working from home work? Evidence from a Chinese experiment. Quarterly Journal of Economics 130(1): 165- 218. https://doi.org/10.1093/qje/qju032

[19] Bailyn, Lotte. 1988. Freeing work from the constraints of location and time. New Technology, Work and Employment 3(2): 143-152. https://doi.org/10.1111/j.1468-005x. 1988.tb00097.x

[20] Dutcher, Glenn. (2012). The Effects of Telecommuting on Productivity: An Experimental Examination. The Role of Dull and Creative Tasks. Journal of Economic Behavior \& Organization. 84. 355-363. https://doi.org/10.1016/j.jebo.2012.04.009

\section{Authors}

Dr. Bibhu Prasad Sahoo is an eminent professor in the University of Delhi (Convenor). He is the head of the Department of Business Economics, SGTB Khalsa College. He has acted as a guide to numerous M.Phil and Ph.D students. He has made a vital contribution in the academic research in the field of commerce and management.

Ankita Gulati is a research scholar pursuing $\mathrm{PhD}$. and teaching as an assistant professor in the Department of Business Economics, S.G.T.B Khalsa College, University of Delhi. Her area of research interest lies in understanding the intersections between technologies and institutional/ public policy, with specific emphasis on the interrelationships between education, invention and innovation.

Irfan Ul Haq is a research scholar pursuing $\mathrm{PhD}$ from the Delhi School of Economics, University of Delhi. His interest lies in the field of accounting research with a special inclination to human resource.

Article submitted 2021-05-12. Resubmitted 2021-06-04. Final acceptance 2021-06-04. Final version published as submitted by the authors. 